\title{
Out of Sight, but Still a Blight? Petroleum Oil Dispersants: Addressing the Environmental Impact
}

\section{Michael G. Goldfeld ${ }^{1 *}$ and Carl W. Podella ${ }^{2}$}

Advanced BioCatalytics Corporation, Irvine, CA, USA

The application of chemical dispersants is considered an important means of accelerating the elimination of petroleum oil spills from the sea surface $[1,2]$. In the recent massive oil leak from the Deepwater Horizon Well incident in the Gulf of Mexico, large amounts of dispersant were used both as a spray, and by direct injection into the bulk of the concentrated oil plumes located deep under the water surface. Dispersants help to speed up the dilution of the oil slick material, and it is often implied that they also accelerate biodegradation of the oil due to an increased interface area between the oil and aqueous phases, thus making the oil more accessible for hydrocarbonoclastic marine microbiota. Removal of the spill from the water surface reduces the impact on birds and mammals occupying that niche.

Most often the prime motivation for using dispersants is to reduce the impact of oil on shorelines, for both economic and environmental reasons: protecting recreational sites, such as sand beaches in resort areas, or sensitive aquatic life as in marshes and shallow waters affected by marine water. In that sense, one might say that the primary outcome from dispersant application is to put the contaminating oil "out of sight", while it may still remain quite an unpleasant "blight", since it's further fate, as well as the environmental impact of the dispersants themselves remain rather obscure.

It must be admitted, that the effect of dispersants on petroleum oil biodegradation is still a matter of dispute. In some studies, dispersants actually inhibited biodegradation. It should also be taken into account that oil dispersions are not indefinitely stable - in fact, they usually separate within about 36 hours, and the standard, EPA approved bench test requires only a 10 minute stability of the dispersion formed, while biodegradation may take weeks or months. If during the rather short dispersion life time substantial dilution has not occurred, then oil may resurface. It is likely that dispersants, in terms of toxicity and biodegradation effects, should be considered taking into account the particular composition of their ingredients, rather than as a class of materials of certain functionality. Recent papers confirm that promotion or suppression of biodegradation is a matter of the surfactant composition in the dispersant itself, the type and condition of the oil slick, as well as the environmental conditions. Unfortunately, bench tests have shown only limited predictive capability of what will be actually the outcome of any particular dispersant application in the field [3].

Having in mind all these limitations and uncertainties, there is a continuing effort in developing dispersants that combine high efficiency with low toxicity and positive effect on petroleum oil biodegradation. Their testing, according to the EPA approved bench tests procedures, is a necessary, if only a preliminary, step to larger scale applications. The magnitude of the oil spill in the Gulf of Mexico certainly gave a strong push to these efforts, sometimes considerably reducing the lag time between the idea and its implications, and a few promising new developments resulted thereof.

In the Alphabetic List of the EPA National Contingency Plan Schedule, the first two lines are occupied by Accell Clean surface washing agent and Accell Clean DWD. The latter is categorized as a dispersant. It met the requirements of the EPA standard efficiency test and showed low aquatic toxicities, rendering it an attractive alternative to other commercially available dispersants. In terms of efficiency, its high status can be seen from table 1, where it is compared (using the same bench procedures) with other products currently on the market [4]. The product is a result of years of studies along one central idea of synergistic enhancement of efficiency of synthetic surfactants by proteins derived from yeast fermentation [5] and new, biologically relevant functionalities resulting from such an enhancement [6].

It has been further found that the same dispersant when

\begin{tabular}{|c|c|c|c|}
\hline \multirow{2}{*}{$\begin{array}{l}\text { Product (1:10 Product-to } \\
\text { Oil ratio) }\end{array}$} & \multicolumn{3}{|c|}{ Dispersant Effectiveness (\% retained after $10 \mathrm{~min}$ ) } \\
\hline & $\begin{array}{c}\text { Prudhoe Bay } \\
\text { Crude }\end{array}$ & $\begin{array}{l}\text { South Louisiana } \\
\text { Crude }\end{array}$ & $\begin{array}{c}\text { Average of Crude } \\
\text { Oils }\end{array}$ \\
\hline Accell囚 Clean DWD & 58.7 & 96.03 & 77.37 \\
\hline Biodispers & 51.00 & 63.00 & 57.00 \\
\hline Corexit $₫$ EC9500A & 45.30 & 54.70 & 50.00 \\
\hline Corexit $囚$ EC9527A & 37.40 & 63.40 & 50.40 \\
\hline Dispersit SPC $1000^{\mathrm{TM}}$ & 40.00 & 100.00 & 73.00 \\
\hline Finasol OSR 52 & 32.50 & 71.60 & 52.10 \\
\hline JD-109 & 26.00 & 91.00 & 58.50 \\
\hline$J D-2000^{\mathrm{TM}}$ & 60.40 & 77.80 & 69.10 \\
\hline Mare Clean 200 & 63.97 & 84.14 & 74.06 \\
\hline Neos AB3000 & 19.70 & 89.80 & 54.80 \\
\hline Nokomis 3-AA & 63.20 & 65.70 & 64.50 \\
\hline Nokomis $3-\mathrm{F} 4$ & 62.20 & 64.90 & 63.56 \\
\hline Saf-Ron Gold & 84.80 & 53.80 & 69.30 \\
\hline Sea Brat \#4 & 53.55 & 60.65 & 57.10 \\
\hline ZI-400 & 50.10 & 89.80 & 69.90 \\
\hline
\end{tabular}

Table 1: Accell ${ }^{\circledR}$ Clean DWD efficiency as dispersant according to a standard bench test with two types of oil, as compared to other dispersants in the EPA NCP listing.

*Corresponding author: Michael G. Goldfeld, Advanced BioCatalytics Corporation, 18010 SkyparkCircle, Irvine, CA 92614, USA, E-mail: MGoldfeld@abiocat.com

Received September 27, 2012; Accepted September 27, 2012; Published September 30, 2012

Citation: Goldfeld MG, Podella CW (2012) Out of Sight, but Still a Blight? Petroleum Oil Dispersants: Addressing the Environmental Impact. J Pet Environ Biotechnol 3:e114. doi:10.4172/2157-7463.1000e114

Copyright: (c) 2012 Goldfeld MG, et al. This is an open-access article distributed under the terms of the Creative Commons Attribution License, which permits unrestricted use, distribution, and reproduction in any medium, provided the original author and source are credited. 


\section{TPH, ppm}

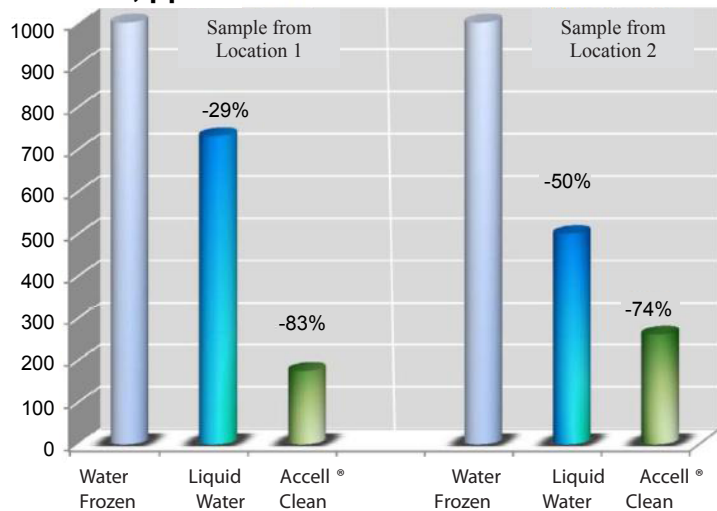

Figure 1: Total petroleum hydrocarbon (TPH) degradation in samples of the ocean water from two locations near Port Fouchon, LA.Incubation for 21 days. Initial level was adjusted to $1000 \mathrm{ppm}$ using $n$-decane. TPH determined by the standard EPA 1664 method.

supplemented with nutrients commonly in deficit in the ocean water (nitrogen, phosphorus and iron), significantly accelerates biodegradation of hydrocarbons in petroleum oil contaminated water by naturally present oil-consuming bacteria. The extent of the total petroleum hydrocarbon digestion by the samples of marine water collected in two locations near Port Fouchon, LA is illustrated in figure 1. Biodegradation is associated with an enhanced bacterial proliferation.

It is essential, that only non-toxic and environmentally friendly surfactants were used in the above formulation (either food grade, or food compatible, in accordance with FDA 21 CFR Parts 182 \& 184 GRAS (Generally Recognized As Safe) and/or FDA 21 CFR 1783400.

This trend of using non-toxic, food grade ingredients in formulations assigned for petroleum oil dispersion, and other large scale industrial applications, is clearly seen in the new product developed by Prof. Robert Lochhead's group at the University of South Mississippi - Hattiesburg [7,8]. Responding to the environmental consequences of the Gulf of Mexico spill, especially the damage to the aquatic birds and other wild life housed at the water surface, these researchers created dispersants based on bilayer-forming surfactants and amphiphilic polysaccharides, using ingredients common in food industry. Once dispersed by these systems, the dispersed oil does not wet, nor spread upon hydrophobic substrates such as oily bird feathers.

No doubt further major efforts in search of dispersant formulations, combining efficiency, environmental safety and economic viability, will result in products that actually will permit us to get the oil spills not only "out of sight" but reliably mitigate both their immediate and longer-term damaging effects.

\section{References}

1. Fingas M (2008) A review of literature related to oil spill dispersants 1997-2008 PWSRCAC, Anchorage, Alaska.

2. Chapman H, Purnell K, Law RJ, Kirby MF (2007) The use of chemical dispersants to combat oil spills at sea: A review of practice and research needs in Europe. Mar Pollut Bull 54: 827-838.

3. U.S. Code of Federal Regulations (CFR). Title 40: Protection of Environment, Pt 300, App. C, pp. 224-246: Swirling flask dispersant effectiveness test, revised standard dispersant toxicity test, and bioremediation agent effectiveness test.

4. US EPA, Emergency Management (2012) Alphabetical List of National Contingency Plan Product Schedule products with Links to Technical Product Summaries.

5. Baldridge JW, Podella, CW, Stuart Krassner, Shuichi Sasaki and Michae Goldfeld (2005) Changing the nature of surfactants: a new paradigm for water processing.

6. Podella CW, Hooshnam N, Krassner SM, Goldfeld MG (2009) Yeast proteinsurfactant complexes uncouple microbial electron transfer and increase transmembrane leak of protons. J Appl Microbiol 106: 140-148.

7. Kemp LK, Lochhead RY, Morgan SE, Savin DA. (2012) Mitigating the coasta ecological damage of spilled oil via oil anti deposition strategies. $244^{\text {th }}$ Amer Chem Soc Natnl Meeting, Philadelphia PA, Aug 2012, Abstract COLL 118.

8. New oil spill dispersant made from ingredients in peanut butter, chocolate, ice cream. Science Daily Aug 2012. 